\title{
Lakasta viljelykasvi?
}

Kalle Hoppula ${ }^{1)}$, Heli Pirinen ${ }^{2)}$ ja Eero Miettinen ${ }^{3)}$

1)MTT Kainuun tutkimusasema, Kipinäntie 16,88600 Sotkamo,kalle.hoppula@mtt.fi

2) ProAgria Kainuu, Osmonkatu 9, 87100 Kajaani, heli.pirinen@proagria.fi

3) MTT Kainuun tutkimusasema, Kipinäntie 16,88600 Sotkamo, eero.miettinen@mtt.fi (virkavapaalla 15.1.2007 saakka, virkavapauden aikainen osoite: MMM, PL 30, 00023 Valtioneuvosto, eero.miettinen@mmm.fi)

\section{Tiivistelmä}

Lakka (Rubus chamaemorus L.) on Pohjois-Suomen arvokkaimpia luonnonmarjoja. Vuosittaiset satovaihtelut ja poimijapula vaikeuttavat marjojen ostajien ja jatkojalostajien toimintaa. Lakan saaminen peltoviljelyyn varmistaisi marjojen tarjontaa, koska luonnossa satovaihtelua aiheuttavat riskitekijät pystytään peltoviljelyssä hallitsemaan paremmin. MTT Kainuun tutkimusasemalla Sotkamossa on tutkittu lakan viljelyn edellytyksiä kenttäkokeissa MTT:n ja ProAgria Kainuun yhteistyönä.

Tässä esitellyt kolme koetta, kasvualustakoe, lannoituskoe sekä lajikekoe, perustettiin MTT Kainuun tutkimusasemalle elokuussa 1999. Vuosina 2001-2004 niistä seurattiin sadontuottoa ja versonkasvua. Kasvualustakokeessa verrattiin lakan kasvua neljässä erilaisessa maalajissa tai kasvualustassa, lannoituskokeessa tutkittiin erikseen N-, P- ja K-lannoituksen vaikutuksia ja lajikekokeessa verrattiin neljää norjalaista lajiketta.

Parhaaksi kasvualustaksi osoittautui vaalean rahkaturpeen ja maatumattoman rahkasammalen sekoitus 1:1. Lakka kasvoi erittäin huonosti kivennäismaassa ( $\mathrm{LjHHt}$ ). Kaksi muuta kasvualustaa, edellä mainitun kivennäismaan ja vaalean rahkaturpeen sekoitus 1:1 sekä kivennäismaan ja maatumattoman rahkasammalen sekoitus 1:1 sijoittuivat tuloksissa näiden kahden käsittelyn välille.

N-, P- tai K-lannoitus ei vaikuttanut lakan sadontuottoon. Vuoteen 2003 saakka lannoitus ei vaikuttanut myöskään lakan versonkasvuun. Vuonna 2004 kokeessa olleen parhaan versotiheyden, noin $600 \mathrm{kpl} / \mathrm{m} 2$, saavuttamiseen tarvittava kasvualustan lannoitusvuoden 2000 typpipitoisuus oli $\geq 600 \mathrm{mg} / \mathrm{l}$, fosforipitoisuus $\geq 30 \mathrm{mg} / 1 \mathrm{ja}$ kaliumpitoisuus $\leq 200 \mathrm{mg} / \mathrm{l}$. Kokeessa testattiin ravinteita vain erikseen. Ravinteiden yhdysvaikutuksia ei testattu.

Lajikekokeessa verrattiin norjalaisia satoa tuottavia emilajikkeita Fjellgull ja Fjordgull sekä pölyttäviä hedelajikkeita Apollen ja Apolto. Emilajikkeista satoisammaksi osoittautui Fjellgull. Versonkasvussa ei ollut lajikkeiden välisiä eroja.

Kokeissa luotiin tarpeellista pohjatietoa lakan viljelyä varten. Lakan viljelyvaatimukset tunnetaan kuitenkin edelleen huonosti ja tutkimustarve on suuri. Vuosina 2005-2007 MTT Kainuun tutkimusasemalla jatketaan edelleen uusissa kokeissa lakan kasvualusta- ja lajikekysymysten selvittämistä.

Asiasanat: Lakka, Rubus chamaemorus, kasvualusta, lannoitus, lajikkeet 


\section{Johdanto}

Lakka (Rubus chamaemorus L.) on Pohjois-Suomen tärkeimpiä ja arvokkaimpia luonnonmarjoja. Suuret vuosittaiset satovaihtelut ja poimijapula vaikeuttavat marjojen ostajien ja jatkojalostajien toimintaa. Lakan, kuten muidenkin luonnonmarjojen, saaminen peltoviljelyyn varmistaisi marjojen tarjontaa, koska luonnossa satovaihtelua aiheuttavat riskitekijät pystytään peltoviljelyssä hallitsemaan paremmin. Luonnossa lakan satotappioita aiheuttavat pääasiassa luonnonkantojen yksineuvoisuudesta johtuvat pölytysongelmat, hallat sekä muut ilmastolliset tekijät ja epätasapaino hede- ja emikasvien välisissä määräsuhteissa.

Luonnossa lakkaa tavataan sekä avoimilla että metsäisillä soilla pohjoisen pallonpuoliskon havumetsävyöhykkeellä. Kasvin maanpäälliset osat ovat yksivuotisia, mutta maarönsyt talvehtivat. Jokainen lakan verso voi tuottaa yhden kukan ja hede- ja emikukat ovat yleensä eri yksilöissä. Kaksineuvoisia yksilöitä, joissa heteet ja emit ovat samassa kukassa, tavataan, mutta ne ovat harvinaisia. Lakka on erittäin talvenkestävä, mutta toisaalta herkkä kasvukauden aikaisille halloille.

Lakan viljelyä on Kainuussa kehitetty vuodesta 1999 alkaen EU:n Interreg IIIA Karjala,- ohjelman ja Euroopan aluekehitysrahaston rahoituksella ProAgria Kainuun ja MTT Kainuun tutkimusaseman yhteistyönä. Nykyinen hanke "Erikoismarjat markkinoille" on järjestyksessä kolmas ja kestää vuoden 2007 loppuun saakka. Lakan viljelymahdollisuuksia on tutkittu aktiivisesti myös Norjassa ja Kanadassa.

Hanketoiminnan tuloksena on saatu lakan viljelyn perusosaamista ja Kainuun alueelle on syntynyt yhteensä noin kolmen hehtaarin verran lakkaviljelmiä. Viljelyyn liittyy kuitenkin vielä lukuisia epävarmuustekijöitä ja viljelyn perusosaamisesta huolimatta lakka on edelleen heikosti tunnettu kasvi. Pitkän aikavälin tavoitteenamme on tehdä lakasta taloudellisesti kannattava viljelykasvi.

MTT Kainuun tutkimusasemalla on tutkittu lakan viljelyn edellytyksiä kenttäkokeissa. Tässä esiteltyjen, vuosina 1999-2004 toteutettujen kenttäkokeiden aiheina ovat olleet kasvualustan maalaji, lannoitus sekä lajikkeet. Uusissa, vuonna 2005 aloitetuissa kenttäkokeissa tutkitaan kasvualustan vesitalouden ja biologisen aktiivisuuden merkitystä sekä testataan hyviä luonnonkantoja.

\section{Aineisto ja menetelmät}

Kesällä 1999 MTT Kainuun tutkimusasemalle (64 6' P, 28²0' I, 157 m merenpinnan yläpuolella) Sotkamoon perustettiin koekenttä, jossa toteutettiin vuosien 1999-2005 aikana kolme eri koetta, kasvualustakoe, lannoituskoe ja lajikekoe. Taimet istutettiin elokuussa 1999 maahan upotettuihin mustiin muovitynnyreihin, joissa yhden tynnyrin oli pohjapinta-ala $0.238 \mathrm{~m}^{2}$ ja syvyys $58 \mathrm{~cm}$. Pohjaveden tasoksi kaikissa koeastioissa säädettiin salaojitusputkien avulla $30 \mathrm{~cm}$ maanpinnan alapuolella. Koekentällä ei käytetty kemiallista kasvinsuojelua ja rikkakasvit kitkettiin pois käsin niiden havaitsemisen jälkeen. Kasvualustakoetta ja lajikekoetta ei lannoitettu missään vaiheessa. Lannoituskokeen ja lajikekokeen kasvualustoina käytettiin vaaleaa rahkaturvetta, jonka maatumisaste oli H3-H4.

Kasvualustakokeessa verrattiin lakan kasvua neljässä erilaisessa kasvualustassa, jotka olivat 1) liejuinen hieno hieta (LjHHt), 2) liejuisen hienon hiedan ja ruskorahkasammaleen (Sphagnum fuscum (Schimp.) Klinggr.) sekoitus suhteessa 1:1 ( $\mathrm{LjHHt}+\mathrm{S}), 3)$ liejuisen hienon hiedan ja vaalean rahkaturpeen (maatumisaste $\mathrm{H} 3-\mathrm{H} 4)$ sekoitus suhteessa 1:1 ( $\mathrm{LjHHt}+\mathrm{T})$ ja 4) vaalean rahkaturpeen (maatumisaste $\mathrm{H} 3-\mathrm{H} 4)$ ja maatumattoman ruskorahkasammalen sekoitus suhteessa 1:1 (T+S). Koeasetelmana kokeessa oli satunnaistettujen lohkojen koe, jossa oli neljä kasvualustakäsittelyä ja viisi lohkoa. Marjovana lajikkeena kokeessa oli 'Fjordgull' (neljä tainta / koeastia) ja pölyttävänä lajikkeena 'Apollen' (yksi taimi/koeastia).

Lannoituskokeessa verrattiin yhdeksää erilaista lannoituskäsittelyä, joissa kasvualustan N-, P- ja K-pitoisuudet olivat erilaisia. Kokeen alussa eri käsittelyjen lannoitteena annetut ravinnemäärät kasvualustalitraa kohden olivat 1) N $200 \mathrm{mg} / \mathrm{l}$, 2) N $400 \mathrm{mg} / 1$, 3) N $600 \mathrm{mg} / \mathrm{l}$, 4) P $10 \mathrm{mg} / 1$, 5) P $20 \mathrm{mg} / \mathrm{l}$, 6) P $30 \mathrm{mg} / \mathrm{l}$, 7) K $200 \mathrm{mg} / \mathrm{l}$, 8) K $400 \mathrm{mg} / 1$, 9) K $600 \mathrm{mg} / \mathrm{l}$. Kasvualustana ollut turve sisälsi ennen lannoitusta $\mathrm{N}<1 \mathrm{mg} / \mathrm{l}, \mathrm{P}<1 \mathrm{mg} / \mathrm{l}$ ja K $16 \mathrm{mg} / \mathrm{l}$. Koeasetelmana kokeessa oli satunnaistettujen lohkojen koe, jossa oli yhdeksän lannoituskäsittelyä ja neljä lohkoa. Lannoituskokeessa marjovana lajikkeena kokeessa oli 'Fjellgull' (neljä tainta/koeastia) ja pölyttävänä lajikkeena 'Apolto' (yksi taimi / koeastia).

Lajikekokeessa verrattiin neljää erilaista norjalaista lajiketta, joista 'Fjordgull' ja 'Fjellgull' olivat marjovia emilajikkeita ja 'Apollen' ja 'Apolto' pölyttäviä hedelajikkeita. Koeasetelmana oli satunnaistettujen lohkojen koe, jossa oli neljä eri käsittelyä (lajiketta) ja viisi lohkoa. Testattavan la- 
jikkeen taimia istutettiin neljä kappaletta kuhunkin koeastiaan. Emilajikkeiden kanssa samaan astiaan ei istutettu erillisiä pölyttäjätaimia kuten muissa kokeissa.

Vuosina 2001-2004 aineistosta mitattiin marjojen kappalemäärät, sadon massat sekä versojen lukumäärät kasvukauden lopussa. Tulosten tilastolliseen analyysiin käytettiin varianssianalyysiä ja SAS 8.01 -tilasto-ohjelmiston proseduuria Mixed. Tilastollisten testien merkitsevyystasona käytettiin kaikissa tapauksissa arvoa $\mathrm{p}<0,05$.

\section{Tulokset ja tulosten tarkastelu Kasvualustakoe}

Kasvualustakoe tuotti satoa vuosina 2003 ja 2004. Parhaat versonkasvu- ja satotulokset saatiin käytettäessä kasvualustana turpeen ja ruskorahkasammalen sekoitusta (Taulukot 1 ja 2). Kivennäismaassa lakan kasvu ja sadontuotto olivat lähes olemattomia.

Taulukko 1. Lakan kasvualustakokeen satotulokset vuosina 2003 ja 2004. Samalla rivillä olevat samalla kirjaimella merkityt arvot eivät eroa toisistaan tilastollisesti $(\mathrm{p}<0.05)$.

\begin{tabular}{llllll}
\hline & \multicolumn{5}{c}{ Kasvualusta } \\
& Vuosi & LjHHT & LjHHt $+\mathrm{S}$ & $\mathrm{LjHH}+\mathrm{T}$ & $\mathrm{T}+\mathrm{S}$ \\
\hline Marjat $\mathrm{g} / \mathrm{m}^{2}$ & 2003 & $1,6 \mathrm{a}$ & $52,0 \mathrm{~b}$ & $3,8 \mathrm{a}$ & $91,3 \mathrm{~b}$ \\
Marjat $\mathrm{g} / \mathrm{m}^{2}$ & 2004 & $0 \mathrm{a}$ & $14,4 \mathrm{a}$ & $0 \mathrm{a}$ & $27,5 \mathrm{a}$ \\
& & & & & \\
Marjat $\mathrm{kpl} / \mathrm{m}^{2}$ & 2003 & $1,7 \mathrm{a}$ & $35,4 \mathrm{~b}$ & $8,4 \mathrm{a}$ & $67,3 \mathrm{c}$ \\
Marjat $\mathrm{kpl} / \mathrm{m}^{2}$ & 2004 & $0 \mathrm{a}$ & $11,8 \mathrm{a}$ & $0 \mathrm{a}$ & $23,6 \mathrm{a}$ \\
\hline
\end{tabular}

Taulukko 2. Lakan kasvualustakokeen versonkasvun tulokset (versoja $\mathrm{kpl} / \mathrm{koeastia)}$ vuosina 20012004. Samalla rivillä olevat samalla kirjaimella merkityt arvot eivät eroa toisistaan tilastollisesti $(\mathrm{p}<0.05)$.

\begin{tabular}{llllll}
\hline & \multicolumn{5}{l}{ Kasvualusta } \\
& Vuosi & LjHHT & LjHHt $+\mathrm{S}$ & $\mathrm{LjHHt}+\mathrm{T}$ & $\mathrm{T}+\mathrm{S}$ \\
\hline Versot $\mathrm{kpl} / \mathrm{m}^{2}$ & 2001 & $8.4 \mathrm{a}$ & $62.3 \mathrm{a}$ & $37.0 \mathrm{a}$ & $64.0 \mathrm{a}$ \\
Versot $\mathrm{kpl} / \mathrm{m}^{2}$ & 2002 & $45.5 \mathrm{a}$ & $238.2 \mathrm{~b}$ & $235.7 \mathrm{~b}$ & $303.1 \mathrm{~b}$ \\
Versot $\mathrm{kpl} / \mathrm{m}^{2}$ & 2003 & $28,6 \mathrm{a}$ & $207,1 \mathrm{~b}$ & $141,4 \mathrm{~b}$ & $262,6 \mathrm{~b}$ \\
Versot $\mathrm{kpl} / \mathrm{m}^{2}$ & 2004 & $20,2 \mathrm{a}$ & $235,7 \mathrm{~b}$ & $158,3 \mathrm{~b}$ & $282,8 \mathrm{~b}$ \\
\hline
\end{tabular}

Oletettavasti lakka vaatii kasvualustaltaan ensisijaisesti hyvää ilmavuutta. Tulosten perusteella tavallinen kivennäismaa ei sellaisenaan sovellu lakanviljelyyn ja turve-kivennäismaa -seoksessakin lakka kasvaa huonosti. Lakka kasvoi tässä kokeessa parhaiten vaalean rahkaturpeen ja ruskorahkasammalen sekoituksessa, joka oli kasvualustoista ilmavin. Lajikekokeessa kasvualustana oli pelkkä vaalea rahkaturve, mutta lajikekokeen Fjordgull-lajikkeen koeruutuihin näitä tuloksia ei voi verrata, koska lajikekokeessa taimitiheys ja emitaimien pölytysolosuhteet olivat erilaiset.

Norjasta saadun tiedon mukaan lakka viihtyy parhaiten heikosti maatuneessa turpeessa, jonka maatumisaste on H1-H4 (Kåre Rapp, suullinen tiedonanto Heli Piriselle 1999). Heikosti maatuneen turpeen ilmavuus on suurin ja siten tieto on yhteensopiva tulostemme kanssa. Turpeen lisäksi kasvualustaksi voisi sopia jokin ilmavuudeltaan hyvä karkea kivennäismaa, koska Lapissa lakkaa esiintyy myös hiekkakankailla. Toisaalta lakan viihtyvyyteen turpeessa voivat vaikuttaa ilmavuuden lisäksi myös muut tekijät, kuten esimerkiksi humuspitoisuus, rahkasammalen lahotessaan vapauttama kalium ja turpeen pehmeys. Käytännössä turve lienee taloudellisesti järkevin kasvualusta.

Koska tavallinen peltomaa ei sovi lakan kasvatukseen, laajamittaista lakanviljelyä on mahdollista harjoittaa vain runsassoisilla seuduilla. Tällä perusteella lakka sopisi vain harvoin perinteisten marjatilojen kasvivalikoimaan. 
Lakan kasvualustan vesi- ja ilmatilavaatimusten selvittäminen jatkuu MTT Kainuun tutkimusasemalle vuonna 2005 perustetussa kokeessa, jossa selvitetään kasvualustan vettymisprofiilin merkitystä.

\section{Lannoituskoe}

Lannoituskoe tuotti satoa vuosina 2003 ja 2004. Kumpanakaan vuonna typen, fosforin tai kaliumin lisääminen ei tilastollisesti vaikuttanut marjojen lukumäärään tai sadon kokonaismassaan. Vuonna 2003 satotaso oli keskimäärin $51,5 \mathrm{~g} / \mathrm{m}^{2}$ ja marjoja oli keskimäärin $40,6 \mathrm{kpl} / \mathrm{m}^{2}$. Vuonna 2004 satotaso oli keskimäärin $46,3 \mathrm{~g} / \mathrm{m}^{2}$ ja marjoja oli keskimäärin $50,6 \mathrm{~g} / \mathrm{m}^{2}$.

Typpi- ja fosforilannoitus lisäsivät tilastollisesti lakan versonkasvua vuonna 2004, mutta kaliumlannoituksella ei ollut vaikutusta. Vuosina 2001-2003 lannoitus ei yhdessäkään tapauksessa vaikuttanut versonkasvuun. Vuonna 2001 versoja oli keskimäärin $69,7 \mathrm{kpl} / \mathrm{m}^{2}$, vuonna 2002 keskimäärin $347,3 \mathrm{kpl} / \mathrm{m}^{2}$ ja vuonna $2003 \mathrm{keskimäärin} 230,8 \mathrm{kpl} / \mathrm{m}^{2}$.

Vuonna 2004 typpi- ja fosforilannoituksen lisääminen lisäsivät versonkasvua (Taulukko 3). Sen sijaan jo pienimmällä kaliumlannoitustasolla saavutettiin hyvä versonkasvu eikä kaliumlannoituksen lisääminen lisännyt versonkasvua.

Taulukko 3. Versojen määrä $\left(\mathrm{kpl} / \mathrm{m}^{2}\right)$ lannoituskokeessa vuonna 2004. Samalla kirjaimella merkityt arvot eivät eroa toisistaan tilastollisesti $(\mathrm{p}<0.05)$.

\begin{tabular}{llll}
\hline & \multicolumn{3}{l}{ Lannoitustaso (1=pienin, $3=$ suurin) } \\
Ravinne & 1 & 2 & 3 \\
\hline $\mathrm{N}$ & $21,0 \mathrm{a}$ & $258,9 \mathrm{bc}$ & $675,6 \mathrm{~d}$ \\
$\mathrm{P}$ & $267,3 \mathrm{bc}$ & $229,4 \mathrm{ab}$ & $629,3 \mathrm{~d}$ \\
$\mathrm{~K}$ & $608,2 \mathrm{~d}$ & $629,3 \mathrm{~d}$ & $467,2 \mathrm{~cd}$ \\
\hline
\end{tabular}

Aiemmissa lakan ravinnetaloutta käsitelleissä tutkimuksissa kaikilla kolmella tärkeimmällä kasvinravinteella, typellä, fosforilla ja kaliumilla, on tutkimuksesta riippuen todettu olevan joko yksin tai yhdessä sadontuottoa lisäävä vaikutus tai nollavaikutus (Rapp 1989, Kortesharju 1986, Kortesharju \& Mäkinen 1986, Kortesharju \& Rantala 1980, Østgård 1964, Lid ym. 1961).

Tässä kokeessa pyrimme selvittämään, muodostuuko typpi, fosfori tai kalium kasvun minimitekijäksi. Lannoitus ei missään vaiheessa vaikuttanut lakan sadontuottoon ja vegetatiiviseen kasvuunkin vaikutusta oli vasta viimeisenä koevuotena. Tuolloin kaikilla testatuilla ravinteilla oli merkitystä lakan vegetatiiviseen kasvuun, mutta jo pienimmällä kaliumlannoitustasolla saatiin yhtä hyvä kasvu kuin suurimmilla typpi- ja fosforilannoitusmäärillä. Versotiheyden $600 \mathrm{kpl} / \mathrm{m}^{2}$ saavuttamiseen tarvittiin kasvualustaan joko typpeä $600 \mathrm{mg} / 1$, fosforia $30 \mathrm{mg} / \mathrm{l}$ tai kaliumia $200 \mathrm{mg} / \mathrm{l}$ tai vähemmän. Ravinteiden yhdysvaikutuksen rooli jää tässä avoimeksi ja nollalannoitustason puuttuminen vaikeuttaa johtopäätösten tekoa. Lannoittamattoman lajikekokeen Fjellgull -lajikkeen koeruutuihin näitä tuloksia ei voi verrata, koska lajikekokeessa taimitiheys ja emitaimien pölytysolosuhteet olivat erilaiset.

Norjassa lakan lannoitusmääriksi suositellaan N 4-8 kg/ha, P 2-4 kg/ha ja K 5-10 kg/ha kerran kymmenessä vuodessa (Rapp 1989). Tässä kokeessa testatut lannoitustasot ovat huomattavasti korkeampia. Fosforin osalta ne sijoittuvat viljavuusluokkiin tyydyttävä, korkea ja arveluttavan korkea ja kaliumin osalta viljavuusluokkiin hyvä, korkea ja arveluttavan korkea.

Marjanviljelyssä yleisesti lannoitustarve on vähäinen ja sadon mukana poistuvien ravinteiden määrä pieni. Lakan luontaiset kasvupaikat ovat myös hyvin vähäravinteisia. Lakan ravinnetarpeen selvittäminen vaatii vielä lisätutkimuksia, koska joissakin tapauksissa lannoituksella on saatu hyötyjä. Vuosina 2005-2007 MTT Kainuun tutkimusasemalla selvitetään kasvien ravinteidenottoa tehostavien kasvualustan biologisten tekijöiden merkitystä lakalle.

\section{Lajikekoe}

Lajikekokeessa satoa tuottivat emilajikkeet Fjellgull ja Fjordgull. Sadontuotoltaan parhaaksi lajikkeeksi sekä sadon massan että marjojen kappalemäärien puolesta osoittautui Fjellgull (Taulukko 4). 
Lakan versonkasvua seurattiin kaikista kokeen lajikkeista (Fjellgull, Fjordgull, Apollen ja Apolto). Lakan versonkasvussa ei ollut lajikkeiden välisiä eroja missään tapauksessa. Vuonna 2001 versoja oli keskimäärin $54,3 \mathrm{kpl} / \mathrm{m}^{2}$, vuonna 2002 keskimäärin $291,7 \mathrm{kpl} / \mathrm{m}^{2}$, vuonna 2003 keskimäärin 144,6 $\mathrm{kpl} / \mathrm{m}^{2}$ ja vuonna 2004 keskimäärin $608,6 \mathrm{kpl} / \mathrm{m}^{2}$.

Taulukko 4. Marjovien emilajikkeiden sadot lakan lajikekokeessa vuosina 2003 ja 2004. Samalla rivillä olevat samalla kirjaimella merkityt arvot eivät eroa toisistaan tilastollisesti $(\mathrm{p}<0.05)$.

\begin{tabular}{llll}
\hline & & Lajike & \\
& Vuosi & Fjellgull & Fjordgull \\
\hline Marjat $\mathrm{g} / \mathrm{m}^{2}$ & 2003 & $81,4 \mathrm{a}$ & $17,6 \mathrm{~b}$ \\
Marjat $\mathrm{g} / \mathrm{m}^{2}$ & 2004 & $135,6 \mathrm{a}$ & $48,0 \mathrm{~b}$ \\
& & & \\
Marjat kpl $/ \mathrm{m}^{2}$ & 2003 & $50,5 \mathrm{a}$ & $12,6 \mathrm{~b}$ \\
Marjat kpl $/ \mathrm{m}^{2}$ & 2004 & $136,4 \mathrm{a}$ & $34,5 \mathrm{~b}$ \\
\hline
\end{tabular}

Kokeessa testatut lajikkeet on julkaistu Norjassa vuonna 1991 (Rapp \& Martinussen 2002, Rapp 1991). Lajikkeiden julkaisijat suosittelevat Norjassa sisämaahan Fjellgull -lajiketta ja rannikolle Fjordgull -lajiketta. Siksi suurimmassa osassa Suomea Fjellgull on luultavasti parempi valinta ja myös MTT Kainuun tutkimusaseman koetulokset tukevat tätä suositusta. Pölyttäjäksi Norjassa suositellaan paikasta riippumatta ensisijaisesti Apolto -lajiketta. Tässä emme kuitenkaan testanneet hedelajikkeiden pölyttämiskykyä ja siksi pölyttäjälajikesuosituksia ei tämän perusteella pystytä antamaan.

Tässä testatut lajikkeet olivat pitkään ainoat markkinoilla olevat lajikkeet. Vuonna 2006 MTT Laukaan tutkimus- ja valiotaimiasema on laskenut markkinoille kaksineuvoisen Nyby -lajikkeen, joka on otettu mukaan vuonna 2005 MTT Kainuun tutkimusasemalle perustettuun lajike/kantavalintakokeeseen yhdessä lupaavien kainuulaisten luonnonkantojen kanssa.

\section{Johtopäätökset}

Lakka vaatii kasvualustaltaan ensisijaisesti runsasta ilmavuutta ja parhaiten lakka kasvaa heikosti maatuneessa turpeessa. Kivennäismaat lienevät yleensä liian tiiviitä kasvualustoja lakalle. Typpi-, fosforija kaliumlannoitukset vaikuttivat tässä kokeessa ainoastaan vegetatiiviseen kasvuun. Sadontuottoa ne eivät lisänneet. Lakan lannoitustarpeen selvittäminen vaatii vielä lisätutkimuksia. Norjalaisista yksineuvoisista lakkalajikkeista Fjellgull menestyi MTT Kainuun tutkimusasemalla paremmin kuin Fjordgull. Lakka on edelleen heikosti tunnettu kasvi, jonka viljelyyn saattaminen vaatii runsaasti lisää tutkimusta.

\section{Kirjallisuus}

Kortesharju, J. 1986. Hillan sato ja kukinta lannoitus- ja olkikatekokeissa Rovaniemen maalaiskunnassa. Folia Forestalia 648. $13 \mathrm{~s}$.

Kortesharju, J. \& Mäkinen Y. 1986. Vaotuksen, lannoituksen ja katteiden vaikutus hillaan karuilla luonnontilaisilla soilla. Folia Forestalia 669. $15 \mathrm{~s}$.

Kortesharju, J. \& Rantala, E.M. 1980. Sijoituslannoituksen vaikutuksesta hillaan (Rubus chamaemorus L.) ojittamattomilla soilla. Suo 31(4): 85-92.

Lid, J., Lie, O. \& Løddesøl, A. 1961. Orienterende forsøk med dyrking av molter. Meddelerser fra Det norske myrselskap 59: 1-26.

Rapp, K. 1991. Seleksjon og sortsutvikling for større bæravling hos molte (Rubus chamaemorus L.). Norsk landbruksforskning 5(4): 359-367.

Rapp, K. 1989. Gjødsling til molte (Rubus chamaemorus L.). Jord og myr 13(4): 109-129. 
SUOMEN MAATALOUSTIETEELLISEN SEURAN TIEDOTE NRO 21

Rapp, K. \& Martinussen, I. 2002. Breeding cloudberry (Rubus chamaemorus L.) for commercial use. Acta Horticulturae 585: 159-160.

Østgård, O. 1964. Molteundersøkelser i Nord-Norge. Forskning og forsøk i landbruget 15: 409-444. 